\title{
The De-marketing Strategies as a Vital Resolve of Antibiotics Misuse Dilemma
}

\author{
Ali Al-Samydai' ${ }^{*}$ (D) Mahmood Jasim AL-Samydai ${ }^{2}$, Maha N. Abu Hajleh ${ }^{3}$ (D), \\ Ihab Ali Qrimea ${ }^{2}$, Abdul Azez Badir Alindawy ${ }^{4}$, Lidia Kamal Al-Halaseh ${ }^{5}$ \\ and Rudaina Othman Yousif ${ }^{6}$ (D)
}

\begin{abstract}
${ }^{1}$ Pharmacological and Diagnostic Research Centre, Faculty of Pharmacy, Al-Ahliyya Amman University, Zip Code - 19328, Amman, Jordan.

${ }^{2}$ Department of Marketing, The Faculty of Business, Al-Zaytoonah University, Amman, Jordan.

${ }^{3}$ Department of Cosmetic Science, Pharmacological and Diagnostic Research Centre, Faculty of Allied Medical Sciences, Al-Ahliyya Amman University, Zip code - 19328, Amman, Jordan.

${ }^{4}$ Department of Business Management, Faculty of Business, Al-Zaytooneh University of Jordan, Amman, Jordan. ${ }^{5}$ Department of Pharmaceutical Chemistry, Faculty of pharmacy, Mutah University, Zip code - 61710, Al-Karak, Jordan.

${ }^{6}$ Founding Commission Member, Al-Zahrawi University College, Karbala - 56001, Iraq.
\end{abstract}

\begin{abstract}
Developing resistance to the currently available antimicrobial agents, particularly anti-Bacterial, is a worrying issue that rises highly worldwide. Communities, health workers, and government officials around the world are joining in, calling for overuse and misuse of antibiotics to stop. The phrase "de-marketing" indicates a strategy that drives to organize the form and the level of the current and future demand; not only that, but rationalizes it by organizations (profit, non-profit organizations as well as governments) specified to discourage and minimize activities of organizations about selling, distribution, using, and advertising... etc. It is to conduct an investigation of the potential impact of demarketing in both controlling and minimizing the antibiotic misusage in Jordan. The essential purpose of the current analysis research is to manifest the contribution of the general demarketing strategy in influencing the attitude of consumers towards rationalization of taking antibiotics through regular medications, which is under the supervision and recommendations of professional doctors. In this article, we focused on those secondary resources derived from the published literature. Besides, we relied on the output of 450 consumers' interactions and responses to our 19 questions distributed as
\end{abstract}

*Correspondence: Phalimahmoud2012@yahoo.com

(Received: July 04, 2021; accepted: September 08, 2021)

Citation: Al-Samydai A, AL-Samydai MJ, Abu Hajleh MN, et al. The De-marketing Strategies as a Vital Resolve of Antibiotics Misuse Dilemma. J Pure Appl Microbiol. 2021;15(4):1898-1906. doi: 10.22207/JPAM.15.4.11

(C) The Author(s) 2021. Open Access. This article is distributed under the terms of the Creative Commons Attribution 4.0 International License which permits unrestricted use, sharing, distribution, and reproduction in any medium, provided you give appropriate credit to the original author(s) and the source, provide a link to the Creative Commons license, and indicate if changes were made. 
a survey with consideration to the general ethics. The model of our study was designed based on the preliminary information collected from exploration study. The insight statistical analysis confirmed a attitude towards rationalization of taking antibiotics without doctor supervision (off prescription) that properly will raise the issue of antibiotics misuse along with its severe and dangerous side effects which will have a possible reduction of the undesirable and toxic effects after misusing the drugs. Moreover, this strategy would have a positive impact in lowering eco-toxicity of antibiotics misuse to words non-target aquatic organisms; plants or sediment and soil-inhabiting organisms. In conclusion, The problem of antibiotic resistance can be minimized only by concerted efforts of all members of society for ensuring the continued efficiency of antibiotics, the demarketing strategy shows a promising approach which could be used by any interested parties working to develop policies, strategies, interventions or campaigns to reduce antibiotic resistance.

Keywords: Advertising campaign, Antibiotics misuse, Toxicity, Attitude, Medications, Consumption, Demarketing strategy

\section{INTRODUCTION}

The rapid emergence and dissemination of resistant bacteria are occurring globally including methicillin-resistant Staphylococcus aureus (MRSA), vancomycin-resistant Enterococcus (VRE), multidrug-resistant (MDR) Pseudomonas aeruginosa, imipenem-resistant Acinetobacter baumannii, and third-generation cephalosporinresistant Escherichia coli and Klebsiella pneumonia, threatening the potency of antibiotics, which saves millions of lives. ${ }^{1,2}$ Bacteria have evolved an array of mechanisms that enable them to resist the inhibitory action of antibiotic, ${ }^{3}$ Antibiotic resistance may occur naturally. Still, overuse of antibiotics accelerates the process leading to the expulsion of sensitive strain and procreation and propagation of the resistant bacteria in the community. Several countries already have taken steps to reduce the misuse of antimicrobials. ${ }^{1}$

Despite these efforts, the volume of antibiotic use is ever-increasing worldwide, especially in developing countries ${ }^{4}$ Therefore, to address the problem of antibiotic resistance, effective strategies are required.

The foundation of demarketing is influencing people and consumers to rationalize their consumption for all different commodities, services, and products. Those who harm people's health and, relatively, society health. This can be done by changing consumer attitude and take it away from irrational consumption. ${ }^{5}$ Such a process can be applied in healthcare and medications. The demarketing concept does not mean order or demand cancellation, but an attempt to reduce consumption of many products that harm health and side effects on people and society by reducing the demand and spread awareness and education among people. ${ }^{6,7}$

On the other hand, defines demarketing is rationalizing consumption or using a specific type of service or product through educating customers on the vital issue of decreasing the consumption of these specific goods and/or services. ${ }^{8}$ Also, this indicates that demarketing uses different theories in marketing science to persuade clients to alter both the attitude and behavior concerning specific items or services. ${ }^{9}$

\section{Literature Review}

A reduction in antibiotic consumption leads to a reduction of resistance. ${ }^{10}$ The classical Finnish study focusing on macrolide resistant Streptococcus pyogenes clearly showed how a reduction in macrolide use could lead to a reduction in AMR. Antibiotic resistance dropped from $9.2 \%$ in 1997 to $7.4 \%$ in 2000 , with a statistically significant association between regional macrolide resistance and consumption rates. ${ }^{11}$

Continuous efforts to educate people about antibiotic resistance are the very important strategy. The multidisciplinary core group, including physicians, pharmacists, microbiologists, epidemiologists and infectious disease specialists, can educate various members of society. prescribers should use antibiotics, based on the recommendation of guidelines. ${ }^{2}$

Prescribers of antimicrobial drugs have dual, somewhat contradictory responsibilities. 
On the one hand they want to offer optimal therapy for the individual patient under their care; on the other hand they have a responsibility to the same and other patients in the future and to public health to preserve the efficacy of antibiotics and minimize the development of resistance. ${ }^{12}$ The former responsibility tends to promote overtreatment; the latter is usually overlooked. Among antimicrobial drugs, those targeting bacteria, i.e., antibiotics, are most extensively developed and prescribed. Misuse of antibiotics, i.e., unnecessary prescriptions as well as inappropriate use (inadequate dosing, wrong duration) is frequent; up to half of the antibiotic prescriptions both in the community and in hospitals are considered unjustified. Bacterial resistance to antibiotics is a serious threat to patients that is increasing rapidly. ${ }^{12,13}$

In the last periods, the concern about demarketing terms increased, reflected in many types of research that approached different subjects, including its effect on many issues that face society, public health, and rationalizing consumption. Many studies' headlines will be demonstrated and approached, directly or indirectly demarketing, to have a complete image about this concept (demarketing) in the way to be useful for our purpose in this article. So, we consider a couple of studies, one of them focuses on examining the drivers of risk behavior, for example, smokers who have a definite negative impact on the economy. ${ }^{15}$ The other study concerned about the influence of the phenomenon of smoking between USA citizens particularly in African American societies. The latter study reported that smokers were illegal smokes in restricted public areas include restaurants and even children parks. Moreover, they refuse any more taxes on cigarettes and other smoking staff. ${ }^{16}$

And at first, we can figure out that people must consume without considering what its harmful and what it's safe, so they are smoking wherever and on other occasions they refuse to complain about what organizations or government want.

As we see in a previous study and in the following one the campaign about awareness people (let them know) was so effective and popular in marketing procedure. ${ }^{18}$ Regarding a study run in Jordan concerning about evaluating the efficient use of demarketing strategies in persuading Jordanian to watch their water consumption, a positive correlation was measured between the awareness campaigns and water rational consumption. The latter study was run by a civil Jordanian organization. ${ }^{8}$

After revising many studies, we find out that demarketing does not positively impact the individual level, but it has an impact on organizations, society, and the world as all. On an organization level; a study concerning about the influence of the apparent demarketing protocols on consumers' minds, found out that all included factors are positively related, in a varying degrees, to the reputation enhancement in consumers' minds ${ }^{7}$ at society and world levels.

Our essential concern in this study is demarketing in the health sector specified about the misuse of antibiotics. As we mention above, there are few articles about tasks such as this. Still, we can use and apply the same methods, concepts, and even factors related to other problems, as previous studies show. To reduce using of antibiotics. That because people, unfortunately, use antibiotics in improper ways, and one of them is using it when having symptoms of flu. ${ }^{18} \mathrm{And}$ there many factors that can be considered as leading to this harmful habit, such as education, experience, economic incentives, wrong diagnosis of diseases, and other factors, which should be appropriately comprehended to establish demarketing strategies effectively. Upon that, there are strategies for decreasing using of antibiotics, one of that reduces the annual approval of new antibiotics, which is a decline from 19 in the 80 s to just 4 in $2014 .{ }^{19}$ So all that we mention above reveling. It is so important to use marketing and its methods, concepts, and strategies to make people decline their use of antibiotics (demarketing in a way to make marketing do what it's supposed to do but to get a completely different result than traditional marketing doing).

This article aims to investigate the potential role of demarketing on controlling and reducing the misuse of antibiotics in Jordan, which many consumers may conduct due to their attitudes towards antibiotics. Due to general or partial information they have, but not the professional opinion which will usually be aware of the case and all side effects of the taken or 
described medicine. while the central hypothesis of this study was "The use of a general demarketing strategy has an impact on antibiotic misuse.'

\section{MATERIALS AND METHODS Methodology}

In this article, we faced some limitation in the process of this research work conductance. One of these, patients/customers on antibiotics have no questions agreement (refuse). Other obstacle was the unclear understanding of the general terms of antibiotic abusing and de- or reverse marketing. The lack of published studies and data on this field was also a limiting factor. In other words, studies that deal with reducing and controlling the consumption of these products to avoid antibiotics misuse complications are relatively rare. ${ }^{20,21}$

\section{Data Collection and Sampling}

In order to explore the variables leading to demarketing strategy in order to have a control on antibiotic purchasing and self-prescription in Jordan; a questionnaire was used as a fundamental basic method for collecting data. The design of this questionnaire was optimized after conducting the study module and its hypotheses. The target societies were Jordanian population including those work for the health sector as pharmacists and physicians. Research team adopted a simple randomized sampling. Copies of the questionnaire were distributed upon this model of selection.

Scaling and determining the study dimensions

The study includes six dimensions:

D1: General demarketing strategy has an impact on controlling and reducing consumption of antibiotic misuse.

D2: Increase of advertising campaigns about Health \& Health care Awareness.

D3: Consumption of antibiotics.

D4: Control on Health \& Healthcare procedures: by the concerned authorities.

D5: Pharmacists Advice.

\section{Study Model}

D6: Physicians (Doctors) Advice.

Modeling this study was format following related published scientific reports..$^{6,22,23}$

\section{Hypotheses of the Study}

All the hypothesis related to the current study were based on the problem, model, previous work combined to the scholar personal experience.
Modern-market and demarketing concepts were also in our consideration. The hypotheses of the study are:

$\mathrm{H}-1$ Utilizing a general demarketing strategy has an impact on antibiotic misuse.

$\mathrm{H}-2$ Increase of advertising campaigns of health awareness has impact on antibiotic misuse. $\mathrm{H}-3$ Consumption of antibiotics has an impact on antibiotic misuse.

$\mathrm{H}-4$ Controlling health and healthcare procedures have an impact on antibiotic misuse. H-5 Pharmacists advice has an impact on antibiotic misuse.

H-6 Physicians advice has an impact on antibiotic misuse.

H-7 Confirmed relation between our study model components.

\section{Research Questions}

Previous reports investigate the application of demarketing strategy on water reservation, electricity usage, cigarette smoking and alcohol consumption, antibiotic abuse, and also on controlled drugs such as narcotic analgesics. There is a lack of scientific evidence on applying the general demarketing strategies in impacting individuals' attitudes towards rationalizing medications consumption and antibiotics, particularly. We aim to answer the following questions through our study research:

1. Has the demarketing strategy plays a role in affecting individuals' attitudes towards rationalization of misuse consumption of antibiotics?

2. Do advertising campaigns about health and healthcare affect people's attitudes towards rationalizing antibiotics misuse?

3. Do consumption of antibiotic misuse affect people's health control on health and healthcare procedures affect reducing antibiotics abuse?

4. Dose pharmacist advice affects reducing antibiotic misuse?

5. Dose physicians' (Doctors) advice affects reducing antibiotic misuse?

6. Does people's perception (awareness) affect their attitudes towards rationalizing antibiotics misuse?

\section{Aims and objectives}

After the high budget spent on antibiotics' medications consumption in countries with 
low-income, the overall research aim is to rationalize the use of antibiotic medication in order to improve the economic status of these poor countries besides decreasing health hazard issues. The study objective is to evaluate the demarketing strategy applications on individuals purchasing attitudes in order to achieve our main aim. The variables investigated during the research work are: the effect of adverts campaigns, folk awareness, pricing policy, and finally directing the customers into alternative local medications.

This research reflected on payments of the budget. This research aims to know the impact of using general strategy demarketing on people (individuals) attitudes towards rationalization of antibiotics consumption by applying many variables like advertising campaigns, people awareness, pricing policy, and local medications as an alternative.

Also, raise the control level on pharmacies, by official authorities, in issuing these medications. What is the role of the pharmacist in issuing antibiotics without a prescription? This question

Table 1. Validity and Measurement of the Tool (Tools validation and measurements)

\begin{tabular}{lcc}
\hline valid samples- & Cronbach's & items- \\
number & $\alpha$ & number \\
\hline
\end{tabular}

\begin{tabular}{lll}
\hline 450 & 0.83 & 19
\end{tabular}

must be included within the controls and the related procedures.

\section{RESULTS}

\section{Tools validation and measurements}

Cronbach's Alpha coefficient was used in conjugation with alpha value $(\alpha=0.83)$ for all the variables studied in this research work. (Table 1 )

(D-1, D-2, D-3, D-4, D-5 and D-6), that corresponds the six hypotheses. The main values of these are $\mathrm{H}-1=3.71, \mathrm{H}-2=3.60, \mathrm{H}-3=4.11, \mathrm{H}-4$ $=3.62, \mathrm{H}-5=4.41, \mathrm{H}-6=4.12$. The recorded values are higher than the scale midpoint (3).

Further validation of the obtained results were took place by one sample t-test in which the overall mean differences of the applied dimensions (as whole) were significantly valid at $(\mathrm{Ns}=0.05)$ with a higher $\mathrm{T}$ value $(\mathrm{H}-1=3.71, \mathrm{H}-2=3.60, \mathrm{H}-3$ $=4.11, \mathrm{H}-4=3.62, \mathrm{H}-5=4.41, \mathrm{H}-6=4.12$ ). These scores are higher than (tabular $=1.96$ ), as a result, the six hypotheses were confirmed. The obtained results are shown in Table 2.

For testing the relation between the constituents/components of our study model; we have adopted the Person correlation coefficient and developed the first hypothesis $(\mathrm{H}-1)$. We found that all the components of our study model are positively and significantly related as shown in shown in Table 3.

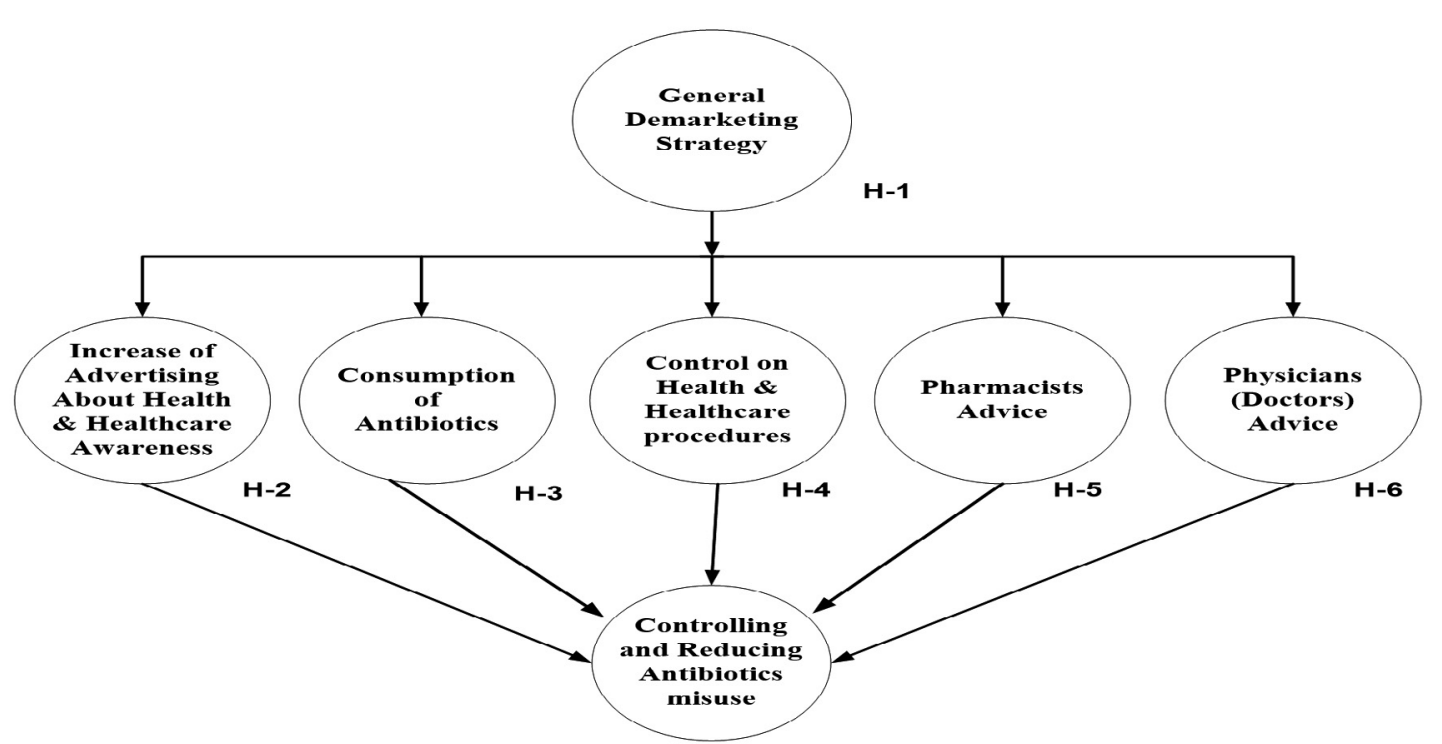

Fig. 1. Study model, shows the dimensions and the relation between them. 


\section{DISCUSSION}

The overall aim of the current study is to investigate and evaluate the demarketing strategy impact upon antibiotic abuse between Jordanians. Therefore, minimizing the demands upon purchasing, importing and using these medications. To achieve our aims, a model study was developed with several variables categorized into six dimensions: general demarketing strategy, advertising campaigns, reduce demand on antibiotics and eliminate the misuse, Control on Health \& Healthcare procedures by the concerned authorities, Pharmacists, Physicians (Doctors). Accordingly, and based on these six dimensions, six hypotheses were developed. Our data analysis was chiefly based on deriving conductive descriptive statistics besides extracting both the mean and the standard deviation. A one-sample t-test was also used in order to check the validity of our six hypotheses. These hypotheses were developed in order to measure the tying-up strength of our model components. Person's correlation coefficient was also included in testing our hypothesis. We have got positive sample responses to the 19 -questions in our survey in a mean of less than 3 for each (midpoint $=3$ ). According to the analysis of the results, dimension number 6 , which is about physicians and doctors, was (Agree) for the people role on antibiotic usage rationalization. This was ordered as the first. The recorded middle mean was the highest (3.93), and the t-value was 10.61. These results were indicating the willingness of people to regulate and rationalize the consumption and self-prescription of antibiotics. The authorities should invest these relatively good results, civil organizations, media and others. Regarding the impact of the demarketing strategy on minimizing the overuse of antibiotics, the first dimension came upon the fifth-order with a recorded mean value of 3.71 and $T$ value of 7.75 . While dimension number 2, regarding the adverts importance, came up in the least (sixth) place in a mean of 3.60 and $T$ value of 6.67 . The latest results confirm that the role of advertisements decreasing medication consumption is not having a significant impact

Table 2. Testing hypotheses

\begin{tabular}{lcccc}
\hline \multirow{2}{*}{ Hypotheses } & \multicolumn{3}{c}{ Test Value =3 } \\
\cline { 2 - 4 } & Mean & Std. Der & t-value & Sig \\
\hline $\begin{array}{l}\text { H-1 The use of general demarketing strategy } \\
\text { has impact on antibiotic misuse }\end{array}$ & 3.71 & 0.70 & 7.75 & 0.00 \\
H-2 Increase of advertising campaigns of & 3.60 & 0.72 & 6.67 & 0.00 \\
$\begin{array}{l}\text { health awareness has impact on antibiotic misuse } \\
\text { H-3 Controlling health and healthcare }\end{array}$ & 4.11 & 0.68 & 12.2 & 0.00 \\
$\begin{array}{l}\text { procedures has impact on antibiotic misuse } \\
\text { H-4 Pharmacists have impact on antibiotic misuse }\end{array}$ & 3.62 & 0.69 & 7.63 & 0.00 \\
H-5 Physicians have impact on antibiotic misuse & 4.41 & 0.71 & 14.91 & 0.00 \\
H-6 all the component of this study mode were & 4.12 & 0.73 & 14.52 & 0.00 \\
significantly related & & & & \\
Mean & 3.93 & 0.70 & 10.61 & \\
\hline
\end{tabular}

Table 3. Pearson Correlation Coefficient

\begin{tabular}{lllllll}
\hline \multicolumn{2}{c}{ Dimension D1 } & D2 & D3 & D4 & D5 & D6 \\
\hline D1 & 1.000 & & & & & \\
D2 & 0.512 & 1.000 & & & & \\
D3 & 0.420 & 0.557 & 1.000 & & & \\
D4 & 0.490 & 0.546 & 0.477 & 1.000 & & \\
D5 & 0.501 & 0.471 & 0.386 & 0.383 & 1.000 & \\
D6 & 0.491 & 0.546 & 0.449 & 0.311 & 0.453 & 1.000 \\
\hline
\end{tabular}

(relatively) on resolving the obstacle, although adverts are a vital factor. Regarding the third dimension, which concerns the demarketing implications for controlling and regulating the use of antibiotics, it was placed fourth among the other dimensions in a mean of 3.7 and a T-value of 7.75. Health and health care role, which represents the fourth dimension, came up third in a mean of 4.12 and T-value of 13.5. The last dimension, which is 
the fifth in our order, came up in the second order; this dimension is concerned with the pharmacist role in this issue. The second place was taken by a mean of 4.12 and a T-value of 14.52. As mentioned earlier, the doctor's role, which represents the sixth dimension, occupies the first order in a measured mean and T value of 4.12 and 14.52, respectively.

Regarding our sixth hypothesis, further evaluation was run using Pearson's correlation coefficient, and it clearly showed that the components of the current study model are in a positive relation. The highest correlation was recorded between advertising for rationalization of antibiotic misuse consumption, in a correlation coefficient value of 0.557 . In addition to an estimation showing about $30-50 \%$ of antibiotic treatments prescribed in hospitals may be unsuitable or unnecessary. ${ }^{24}$ Main problem is that many antibiotics could be through pharmacies without prescriptions like over the counter medication. This wrong attitude will increase the number of bacteria resistance to even the most potent antibiotics available, and this will reflect on badly health and economy of many countries ${ }^{25}$; this study made it clear that using a general demarketing strategy could play an impact on controlling and reducing antibiotic misuse demand by increasing consumer beliefs, knowledge and awareness may be related to their behaviours regarding the use of antibiotics, which could change their attitudes in future.

In addition, the campaign aimed to examine how their beliefs, knowledge and awareness may be related to their behaviours regarding the use of antibiotics in infections. Finally, the campaign sought to reinforce the key messages about appropriate use of antibiotics in targeted populations.

\section{CONCLUSIONS}

Bacterial resistance and the vast efforts on research concerning inventing new antibiotic lines are the main highlighted issues that urge the health communities worldwide to prioritize a comprehensive reconsideration of the antibiotic abuse within folk.

The general demarketing strategy is a promising concept to develop theories based on and focused on consumers to resolve the risk of medication abuse. Individual sanctification and loyalty to his organization and countries resources need to be improved.

Our study represents an early alert to this problem and an attempt to understand and resolve it by using the concept of general demarketing strategies. The ultimate aim is to regulate antibiotic prescriptions and to minimize the demands on them.

The obtained results showed a positive correlation among the variables used in this study model. This relationship has a variable value in the used correlation coefficient. Additionally, the measured variables were chosen and distributed according to their expected role in minimizing the demand for medications, particularly antibiotics abuse.

The current analysis study is considered one of few studies discussing and manipulating a vital situation that impacts people's health, concerned with unjustified consumption of antibiotics. This act probably will destroy the body's immunity (his natural resistance). This study focuses on the general demarketing role in reducing this group of medications by increasing people's awareness of antibiotics' risks and side effects. Also, the study concentrates on activation of control procedures, within health \& healthcare procedures, by the concerned authorities, on dealing with issuing medications in general and antibiotics. Also, it considers pharmacists and Physicians (Doctors) as significant components in the study model due to their involvement and responsibility in the whole process. Finally, we should concern and other researchers about people's knowledge, which plays an essential role in rationalizing their behaviours (not about using antibiotics only). And that is because people rely on the information they have, what experience they try, and the people they contract with. So that responsibility on physicians and health organization at first (make campaigns and use media, and other tools they can throw it reach the people) then it's the responsibility of people (to have the knowledge and take it from reliability sources), and all of that because the nature of human being, which is, they will not change their behaviour if they do not change their knowledge. 


\section{ACKNOWLEDGMENTS}

None.

\section{CONFLICT OF INTEREST}

The authors declare that there is no conflict of interest.

\section{AUTHORS' CONTRIBUTION}

All authors listed have made a substantial, direct, and intellectual contribution to the work, and approved it for publication.

\section{FUNDING}

None.

\section{DATA AVAILABILITY}

All datasets analyzed in the study are included in the manuscript and presented as tables and figures.

\section{ETHICS STATEMENT}

Not applicable.

\section{REFERENCES}

1. Malik B, Bhattacharyya S. Antibiotic drug-resistance as a complex system driven by socio-economic growth and antibiotic misuse. Scientific Reports. 2019;9(1):15184. doi: 10.1038/s41598-019-50846-1

2. Lee CR, Cho IH, Jeong BC, Lee $\mathrm{SH}$. Strategies to minimize antibiotic resistance. Int J Environ Res Public Health. 2013;10(9):4274-4305. doi: 10.3390/ijerph10094274

3. Wilson DN, Hauryliuk V, Atkinson GC, O'Neill AJ. Target protection as a key antibiotic resistance mechanism. Nat Rev Microbiol. 2020;18(11):637-648. doi: 10.1038/ s41579-020-0386-z

4. AL-Samydai AMJ. Jordanian medicinal plants as an alternative source for new antimicrobials against multi drug resistant: review. Int J Pharmacognosy. 2018;5(9):581-589. doi: 10.13040/IJPSR.0975-8232. IJP.5(9).581-89

5. Medway D, Warnaby G, Dharni S. Demarketing places: Rationales and strategies. Journal of Marketing Management. 2010;27(1-2):124-142. doi: 10.1080/02672571003719096

6. AL-Samydai M, Yousif R. The Role of Demarketing in Reducing Electricity Demand. International Journal of Business and Management. 2018;13(1):209-217. doi: 10.5539/ijbm.v13n1p209

7. Alsamydai MJ. The impact of Ostensible Demarketing strategy on improving product reputation in customer's minds. International Review of Management and Business Research. 2015;4(4):973-988.

8. Yousif R. Measuring the effectiveness of demarketing in influencing consumer behavior of individuals. International Journal of Business Management \& Research. 2014;4(5):31-44.
9. Wall AP. Government "demarketing" as viewed by its target audience. Marketing intelligence \& planning. 2007;25(2):123-135. doi: $10.1108 / 02634500710737915$

10. Llor C, Bjerrum L. Antimicrobial resistance: risk associated with antibiotic overuse and initiatives to reduce the problem. Therapeutic Advances in Drug Safety. 2014;5(6):229-241. doi: $10.1177 / 2042098614554919$

11. Lucien MA, Canarie MF, Kilgore PE, et al. Antibiotics and antimicrobial resistance in the COVID-19 era: Perspective from resource-limited settings. Int J Infect Dis. 2021;104:250-254. doi: 10.1016/j.ijid.2020.12.087

12. Pulcini C, Gyssens IC. How to educate prescribers in antimicrobial stewardship practices. Virulence. 2013;4(2):192-202. doi: 10.4161/viru.23706

13. Al-Samydai A, Hajleh MA, Akour A, Alabdallah $N$, Yousef M, Baqa'in G, Al-saadi A, Al-Halaseh LK, Aburjai T. Phytotherapeutic Approaches and Ethnopharmacological Responses Against COVID-19. Trop J Nat Prod Res. 2021; 5(7):1208-1214. doi. org/10.26538/tinpr/v5i7.7

14. Sagar GA, Joshi A, Kumar S, Shinde M, Singh K, Nautiyal $A$. variation of atmospheric parameters and dependent nature of covid-19 pandemic in india during the lockdown period. J Crit Rev. 2020;7(19):2445-2453. doi: 10.31838/jcr.07.19.297.

15. Bourdeau BL, Brady MK, Cronin Jr JJ. A new frontier in the battle against smoking: An exploratory investigation of low-income adult smokers. Journal of Nonprofit \& Public Sector Marketing. 2006;16(12):123-149. doi: 10.1300/J054v16n01_07

16. Lee D, Cutler BD, Burns J. The marketing and demarketing of tobacco products to low-income African-Americans. Health Marketing Quarterly. 2004;22(2):51-68. doi: 10.1300/J026v22n02_04

17. Salman FM. Effect of demarketing on rationalization of electricity consumption in Jordan (Doctoral dissertation, Thesis for Master's degree in Marketing, Zarqa University, Jordan).2015.

18. Almeman AA, Aljofan M. Direct-To-Physician Advertising and Antibiotic Utilization in Upper Respiratory Tract Infection: A Critical Analysis. Pharm Anal Acta. 2013;4:259. doi: 10.4172/21532435.1000259

19. Ventola CL. The antibiotic resistance crisis: part 1: causes and threats. Pharmacy and Therapeutics. 2015;40(4):277-283.

20. Al-Samydai MJ, Qrimea IA, Yousif RO, Al-Samydai A, Aldin MK. The Impact of Social Media on Consumers' Health Behavior Towards Choosing Herbal Cosmetics. J Crit Rev. 2020;7(9):1171-1176. doi: 10.31838/ jcr.07.09.214

21. Aburjai T, Yousif RO, AISamydai MJ, Al-Samydai A, AlMamoori F, Azzam H. Protein supplements between consumer's opinion and quality control: an applied study in Jordan. Int J Res Pharma Sci. 2019;10(3):19611969. doi: 10.26452/ijrps.v10i3.1402

22. Armstrong Soule CA, Reich BJ. Less is more: is a green demarketing strategy sustainable?. Journal of Marketing Management. 2015;31(13-14):1403-1427. doi: 10.1080/0267257X.2015.1059874 
23. Andre M, Vernby A, Berg J, Lundborg CS. A survey of public knowledge and awareness related to antibiotic use and resistance in Sweden. J Antimicrob Chemother. 2010;65(6):1292-1296. doi: 10.1093/jac/dkq104

24. Pulcini C, Cua E, Lieutier F, Landraud L, Dellamonica P, Roger PM. Antibiotic misuse: a prospective clinical audit in a French university hospital. Eur J Clin Microbiol Infect Dis. 2007;26(4):277-280. doi: 10.1007/ s10096-007-0277-5

25. Al-Samydai M, Al-kholaifeh A, Al-Samydai A. The Impact of Social Media in Improving Patient's Mental Image Towards Healthcare Provided by Private Hospitals' in Amman/Jordan. Indian J Public Health Res Dev. 2019;10(2):491-496. doi: 10.5958/09765506.2019.00339.5 